\title{
Perforator propeller flaps in lower limb reconstruction: a literature review and case reports
}

\author{
Mario F. Scaglioni ${ }^{1}$, Aljosa Macek² \\ 'Department of Hand- and Plastic surgery, Luzerner Kantonsspital, Lucerne 6000, Switzerland. \\ ${ }^{2}$ Department of Surgery, Spital Männedorf, Männedorf 8708, Switzerland.
}

Correspondence to: Dr. Mario F. Scaglioni, Department of Hand- and Plastic Surgery, Luzerner Kantonsspital, Spitalstrasse 16, Lucerne 6000, Switzerland. E-mail: mario.scaglioni@gmail.com

How to cite this article: Scaglioni MF, Macek A. Perforator propeller flaps in lower limb reconstruction: a literature review and case reports. Plast Aesthet Res 2019;6:27. http://dx.doi.org/10.20517/2347-9264.2019.41

Received: 18 Oct 2019 First Decision: 4 Nov 2019 Revised: 7 Nov 2019 Accepted: 14 Nov 2019 Published: 29 Nov 2019

Science Editor: Matthew L. Iorio Copy Editor: Jing-Wen Zhang Production Editor: Tian Zhang

\begin{abstract}
Perforator-pedicled propeller flaps, which base their blood supply on isolated perforators, have been gaining popularity among plastic surgeons over the past two decades. They have proven to be of great value in the reconstruction of soft tissue defects in different areas of the body but are, thanks to their maximal mobility, mostly used in the reconstruction of extremities. In this article, we focus on perforator-pedicled propeller flaps in lower limb reconstruction, where they can be implemented in the coverage of primary as well as secondary soft tissue defects. Firstly, a brief literature review on evolution of propeller flap use in lower extremity is provided. Moreover, we present our surgical technique including the use of indocyanine green real-time angiography for reliable flap transfer. In addition, we report 3 cases of patients in whom we used a local propeller flap for the closure of skin defects in different parts of the leg.
\end{abstract}

Keywords: Propeller flap, perforator flap, local flap, lower limb reconstruction, microsurgery

\section{INTRODUCTION}

Reconstruction of soft tissue defects in the lower limb is known to be difficult due to the lack of spare local tissue in the immediate vicinity of such defects ${ }^{[1]}$. Traditionally, these defects used to be covered, depending on the location, size, and the underlying tissue, by split skin grafts, local transposition flaps, or free flaps ${ }^{[2-4]}$. All of the above have their obvious drawbacks and limitations; thus, over the past two decades, perforator propeller flaps have been gaining popularity among reconstructive surgeons.

cC) (C) The Author(s) 2019. Open Access This article is licensed under a Creative Commons Attribution 4.0 International License (https://creativecommons.org/licenses/by/4.0/), which permits unrestricted use, sharing, adaptation, distribution and reproduction in any medium or format, for any purpose, even commercially, as long as you give appropriate credit to the original author(s) and the source, provide a link to the Creative Commons license, and indicate if changes were made.

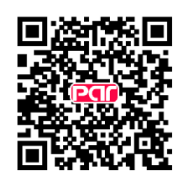


The first authors to use the term "propeller flap" were Hyakusoku et al. ${ }^{[5]}$ in 1991 . His group designed an adipocutaneous flap with a skin island of a length largely exceeding its width, based on a random pedicle in the center, on which the flap was then rotated through $90^{\circ}$ similar to a propeller to release burn scar contractures in the cubital and axillary regions.

Thanks to the advances in microsurgical techniques and anatomical knowledge, perforator flaps have been developed, where a skin island flap is harvested without the underlying muscle. Koshima and Soeda ${ }^{[6]}$ were the first to use the name "perforator flaps" in 1989 and since then perforator flaps have broadened our armamentarium in reconstructive microsurgery.

The two terms were first combined by Hallock ${ }^{[7]}$ in 2006 when he described an adductor perforator flap of the posteromedial thigh designed in a propeller fashion for coverage of ischial or trochanteric pressure sores. This flap was comparable in shape to the one developed by Hyakusoku, but it was based on a skeletonized perforator and rotated through $180^{\circ}$.

Already in the $1990 \mathrm{~s}, \mathrm{TeO}^{[8]}$ greatly developed the surgical technique of perforator-based propeller flap in the reconstruction of the distal third of the lower limb (without having named it as such) and more recently also contributed to the definition.

What is a propeller flap? By the definition of the "Tokyo" Consensus on Propeller Flaps ${ }^{[9]}$ from 2011, a propeller flap is an island flap that reaches the recipient site through an axial rotation of more than $90^{\circ}$. It can be thought of as a propeller with 2 blades of unequal length with the perforator forming the pivot point. Pignatti et al. ${ }^{[9]}$ proposed a further classification based on the nourishing pedicle (subcutaneous, perforator and supercharged), degree of rotation of the skin island $\left(90^{\circ}-180^{\circ}\right)$, and the artery of origin of the perforator vessel (as defined for perforator flaps by the "Gent" consensus ${ }^{[10]}$ ).

Due to the conus-like shape of the lower leg, there is a shortage of local soft tissue for reconstruction of defects. Using a proximally based peninsular fasciocutaneous flap, it is difficult to get a sufficient amount of healthy tissue into the defect without exposing the anterior tibial crest or the Achilles tendon, both of which are difficult to graft. The propeller flap circumvents these challenges/problems by transferring healthy tissue from the proximal calf into the primary defect. Thus, the secondary defect is moved to the area over the proximal muscle bellies, which is easily graftable or even primarily closed, either through a direct mobilization and closure of the skin or even through another propeller flap, as already described by our department ${ }^{[11]}$. Another advantage of the propeller flap, compared to the local flap, is that it avoids the awkward twisting at the base of the flap. This twist is unsightly, and it might even compress or stretch the pedicle, which may endanger the flap survival. Furthermore, the propeller flap design expands the reach of the flap and enables an easier inset.

\section{SURGICAL TECHNIQUE}

Preoperatively, the most appropriate perforator is identified using CT-angiography and a handheld Doppler device. With the perforator used as the pivot point, a provisional flap design is drawn. First, the proximal limit of the flap is determined by transposing the distance between the perforator and the distal border of the defect proximally over the axis of the source artery and adding $1 \mathrm{~cm}$ to that length. Thus, the flap is easily inset without tension and allowed to contract. Next, the width of the proximal flap is determined by measuring the width of the defect and adding $0.5 \mathrm{~cm}$ for the same reason. A thigh tourniquet is used but without exsanguination of the limb, which makes for an easier identification and dissection of the perforator. The raising of the flap begins with an initial exploratory incision under loupe magnification and, thereupon, usually several potentially applicable perforators are found. Based on the position and size, the best one is chosen, and it may not necessarily be the one identified on Doppler sonography. The design of 

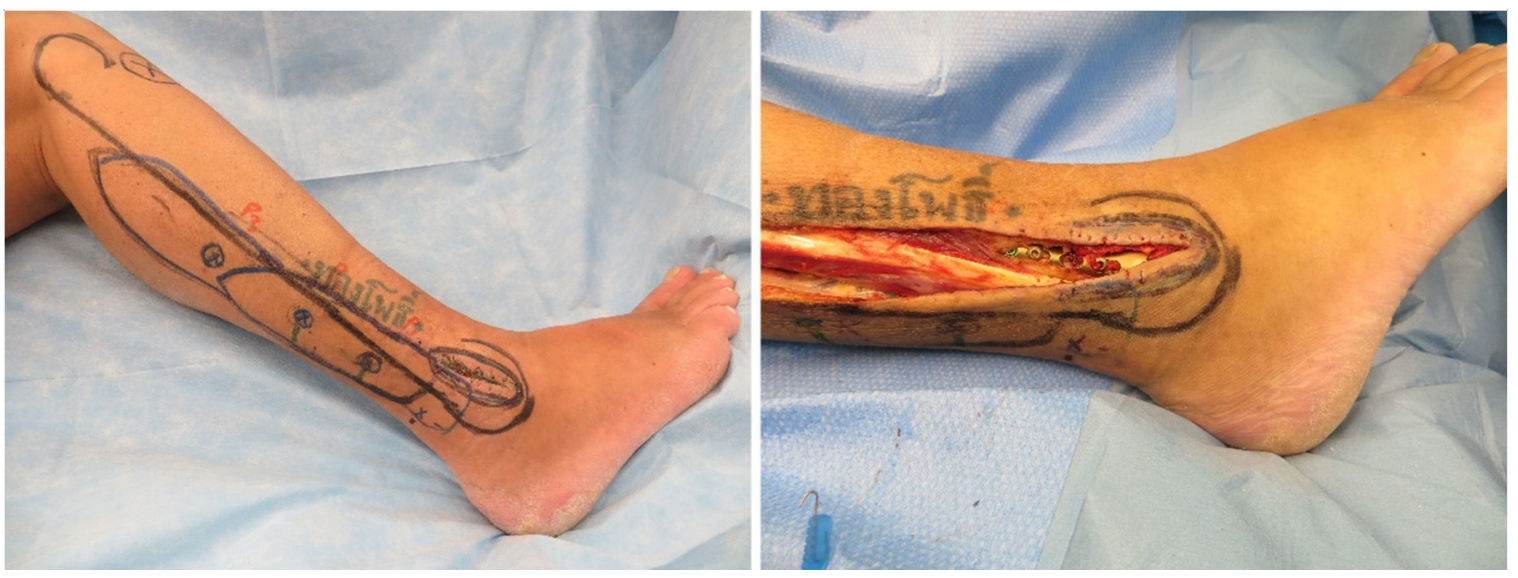

Figure 1. Wound dehiscence with plate exposure after plate osteosynthesis of a lateral malleolus

the flap can be adjusted accordingly. Perforators enclosed in scar or granulation tissue should be avoided. Once the appropriate perforator is chosen, it is carefully prepared and freed of all muscular side branches for at least $2 \mathrm{~cm}$. Wherever feasible, the pedicle is cleaned all the way from the flap to its source vessel. After the flap is islanded, it is inset into the defect and the tourniquet is released. When rotating the flap $180^{\circ}$, the surgeon turns it in both directions to evaluate which rotational direction exerts less extrinsic compression on venae comitantes. Once the decision regarding the rotation is made, two skin sutures are placed on either side of the flap axis. At this point, the perfusion of the flap is controlled using the indocyanine green real-time angiography. Firstly, 2 mL of ICG (Indocyanine green by Verdy ${ }^{\circ}$ ) is administered intravenously, followed by $10 \mathrm{~mL}$ of normal saline. Using a near-infrared camera (Fluobeam ${ }^{\circledR}$ by Fluoptics Grenoble, France), the blood supply of the flap is recorded. Firstly, the arterial perfusion is evaluated. Parts of the flap, which present dark under the Fluobeam, are cut away. Twenty minutes after ICG administration, the flap is checked once again. It is of foremost importance to look for wash-out, and, if the flap is still fluorescent, it is a sign of venous congestion. If the isolated perforator is not providing a sufficient arterial inflow or a sufficient venous outflow, an extra pedicle can be added, as described by Pignatti et al. ${ }^{[9]}$ and lida et al ${ }^{[12]}$ In the case of an insufficient arterial inflow, an extra artery can be microsurgically anastomosed to a second arterial pedicle of the flap. When there is no wash-out on ICG, the pedicle is further dissected and cleaned of all the fibrous bands and, if this is insufficient, a superficial or perforating vein of the flap can be microsurgically anastomosed to a recipient vein to increase the blood flow. Thereafter, the wound closure is straightforward. However, it is important not to close the donor site too tightly as it might endanger the blood supply of the flap through the tourniquet effect.

\section{CASE REPORTS}

\section{Case 1: peroneal artery perforator propeller $180^{\circ}$ flap}

A 41-year-old male patient underwent plate osteosynthesis of a lateral malleolus due to trauma and developed a wound dehiscence with plate exposure [Figure 1]. The plate was removed and, after debridement, a new one was implanted. A local perforator flap measuring $16 \mathrm{~cm} \times 4 \mathrm{~cm}$, based on a Y-shaped perforator of the peroneal artery perforator [Figure 2], was harvested and propelled $180^{\circ}$ into the defect [Figure 3]. In this way, the soft tissue defect from the debridement and the plate were covered with an undamaged tissue. After the inset of the flap, an intraoperative ICG angiography was performed, confirming a good blood perfusion of the whole flap [Figure 4]. The patient's postoperative recovery was unremarkable. He was able to ambulate with no restriction and limitation at six-month follow-up [Figure 5].

\section{Case 2: posterior tibial artery perforator propeller $180^{\circ}$ flap}

A 24-old-male patient sustained a penetrating injury of her right leg, dorsally to the medial ankle. After debridement and a period of wound care, a deep, circle-shaped soft tissue defect measuring $4 \mathrm{~cm} \times 3.5 \mathrm{~cm} \times 2.5 \mathrm{~cm}$ 

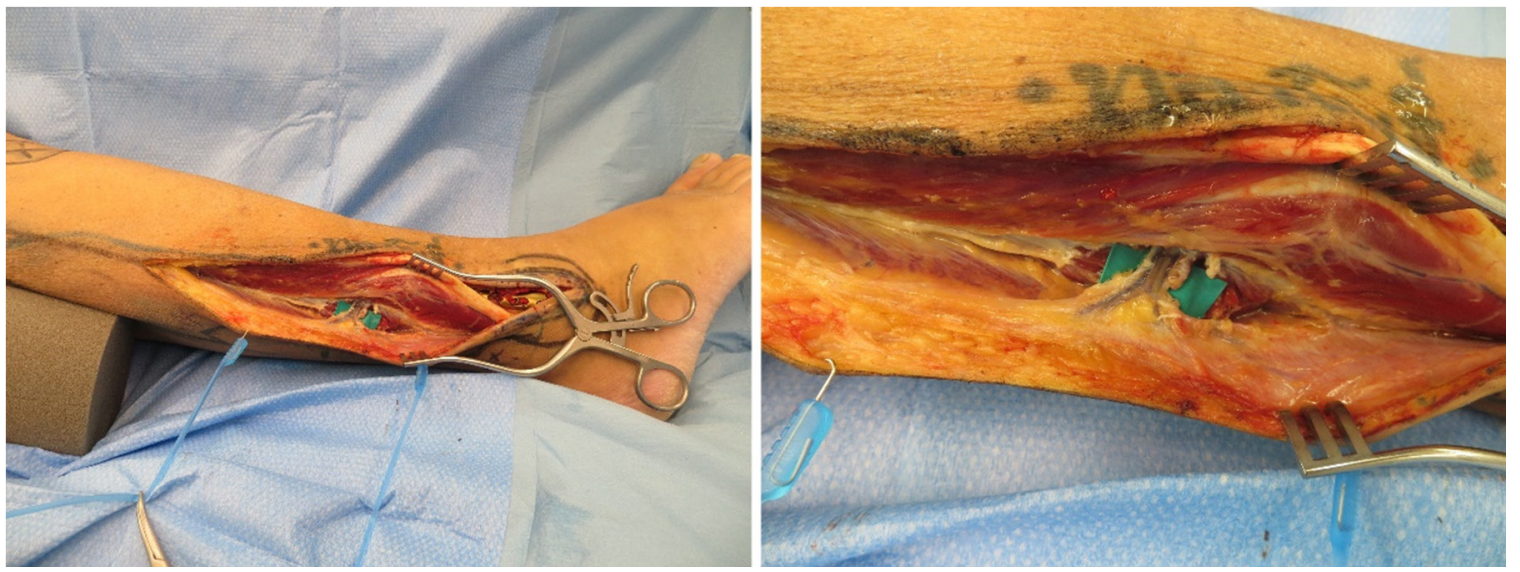

Figure 2. Perforator flap measuring $15 \mathrm{~cm} \times 5 \mathrm{~cm}$ is raised, based on a Y-Shape perforator of peroneal artery
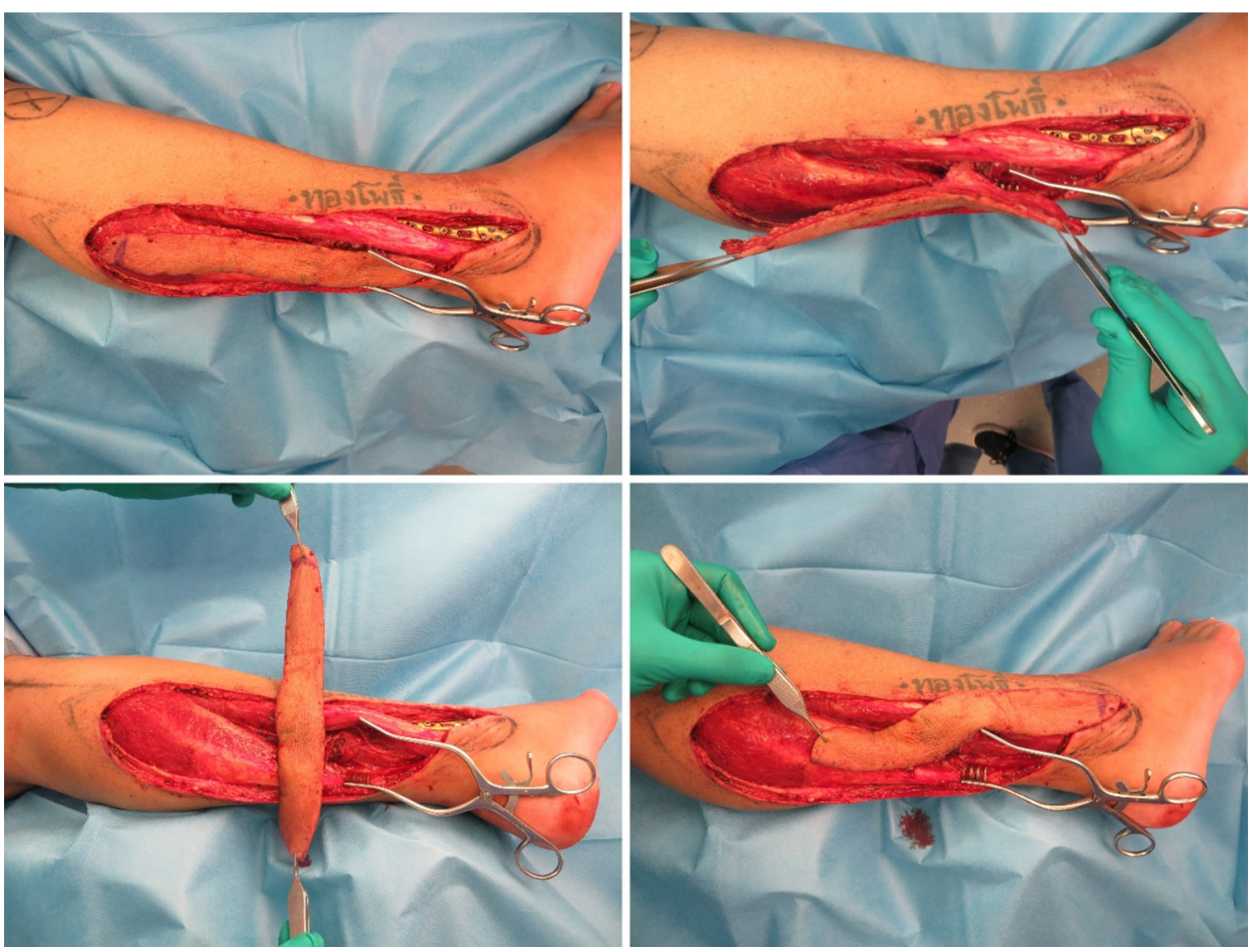

Figure 3. The peroneal artery perforator flap is effortlessly propelled into the defect by $180^{\circ}$

was noted, with Achilles tendon and calcaneus bone exposure [Figure 6, upper left]. A local perforator flap based on the posterior tibial artery measuring $12 \mathrm{~cm} \times 4 \mathrm{~cm}$ was designed. Two appropriate perforators were found [Figure 6, upper right]. Based on the size and location farther from the defect, the proximal one was chosen. The proximal part of the flap was de-epithelized [Figure 6, lower left], the flap was propelled for $180^{\circ}$, and the de-epithelized part of the flap was used to fill the deep defect [Figure 6, lower right]. The donor site could be closed directly [Figure 7, left]. The wound healed uneventfully. Ambulation was permitted five days postoperatively with a VACOped ${ }^{\oplus}$ leg cast for 4 weeks to prevent wound dehiscence through the 

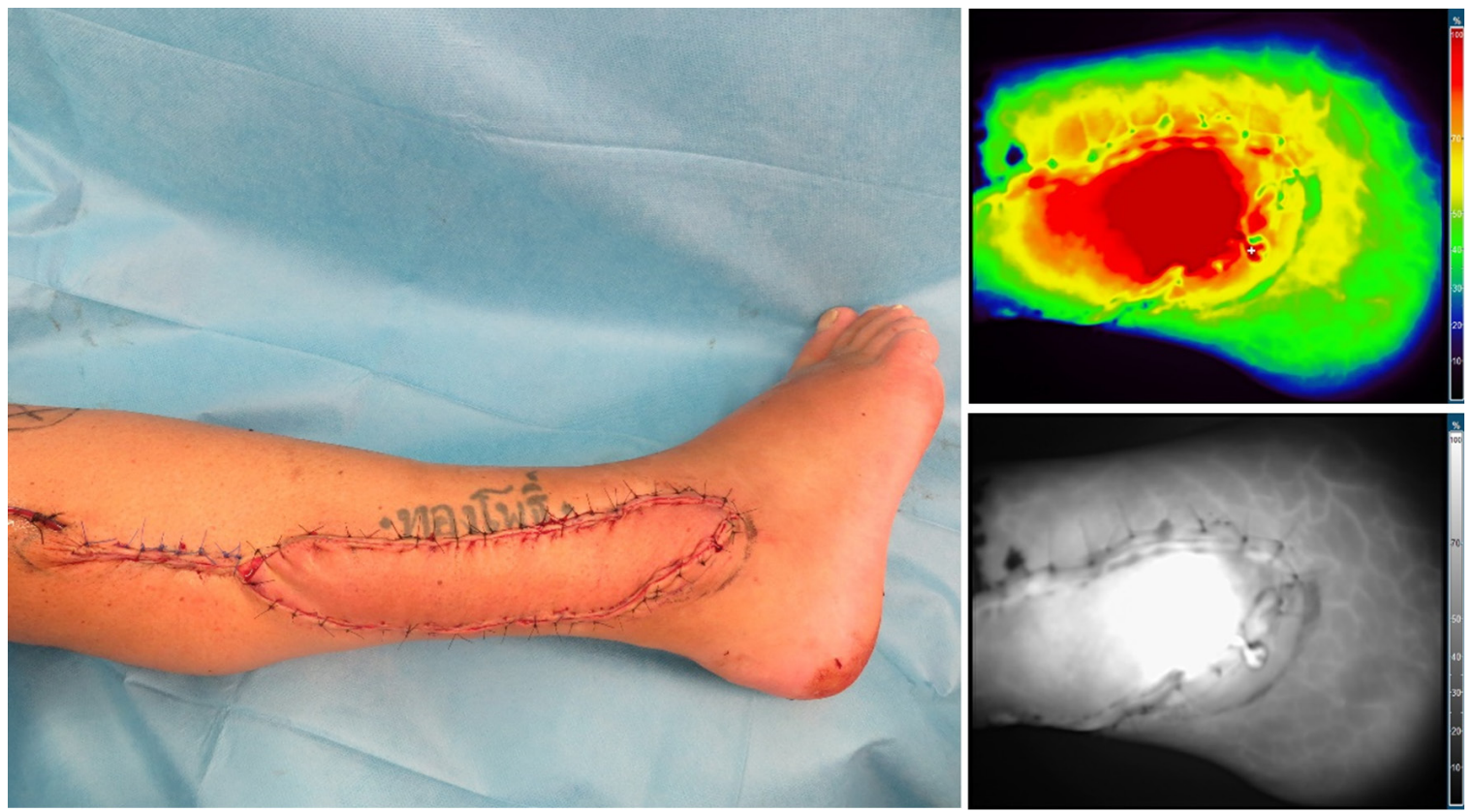

Figure 4. Left: immediate postoperative result, showing the donor site was closed directly. Right: indocyanin green angiography for blood perfusion at the tip of the flap after flap insetting
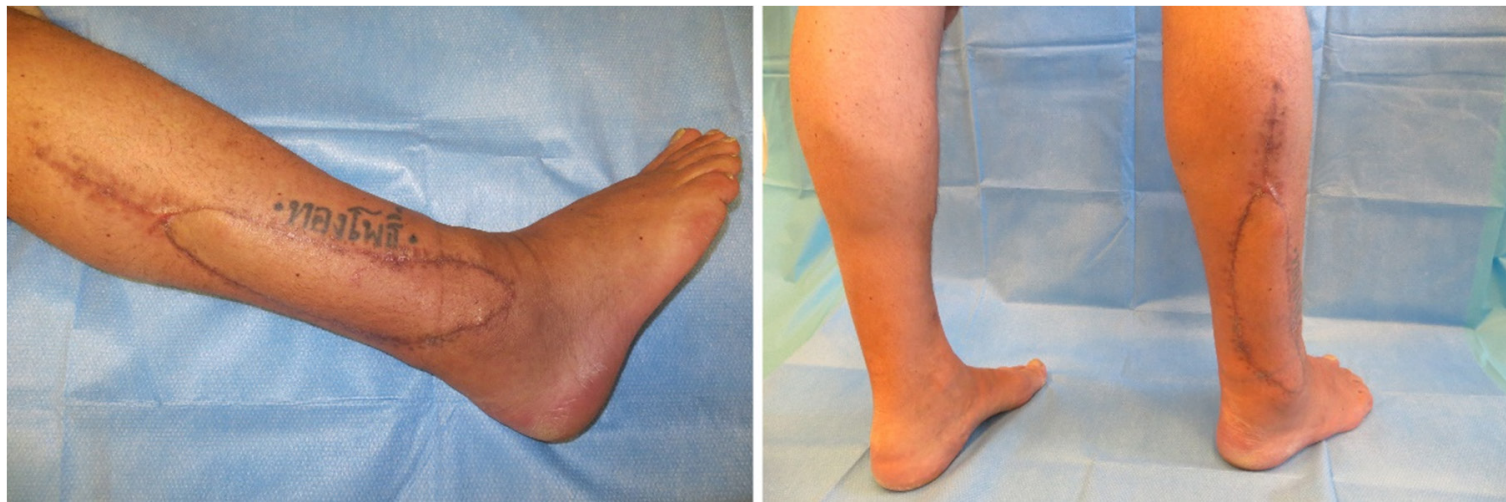

Figure 5. Follow-up at 6 months, showing no functional deficit and good cosmesis

shearing force of the Achilles tendon. The flap survived completely at four-month follow-up [Figure 7, right].

\section{Case 3: anterolateral thigh propeller flap}

A 66-old female patient was presented to us with a large synovial sarcoma of the right lateral thigh [Figure 8, upper left]. She had already undergone radiotherapy preoperatively. Tumor excision and defect reconstruction with a pedicle anterolateral thigh perforator propeller flap were planned in the same setting. The defect following tumor excision measured $12 \mathrm{~cm} \times 7 \mathrm{~cm}$ [Figure 8, upper right]. A pedicle anterolateral thigh flap measuring $14 \mathrm{~cm} \times 8 \mathrm{~cm}$, based on a perforator of the descending branch of the lateral femoral circumflex artery, was raised [Figure 8 , lower left]. The flap was rotated $130^{\circ}$ in counter clockwise direction and inset into the defect, covering it without tension [Figure 8, lower right]. The donor site could be closed directly [Figure 9, left]. The wound healed well, the patient was cancer free, and no gait disturbance was observed five months after the operation [Figure 9, right]. 

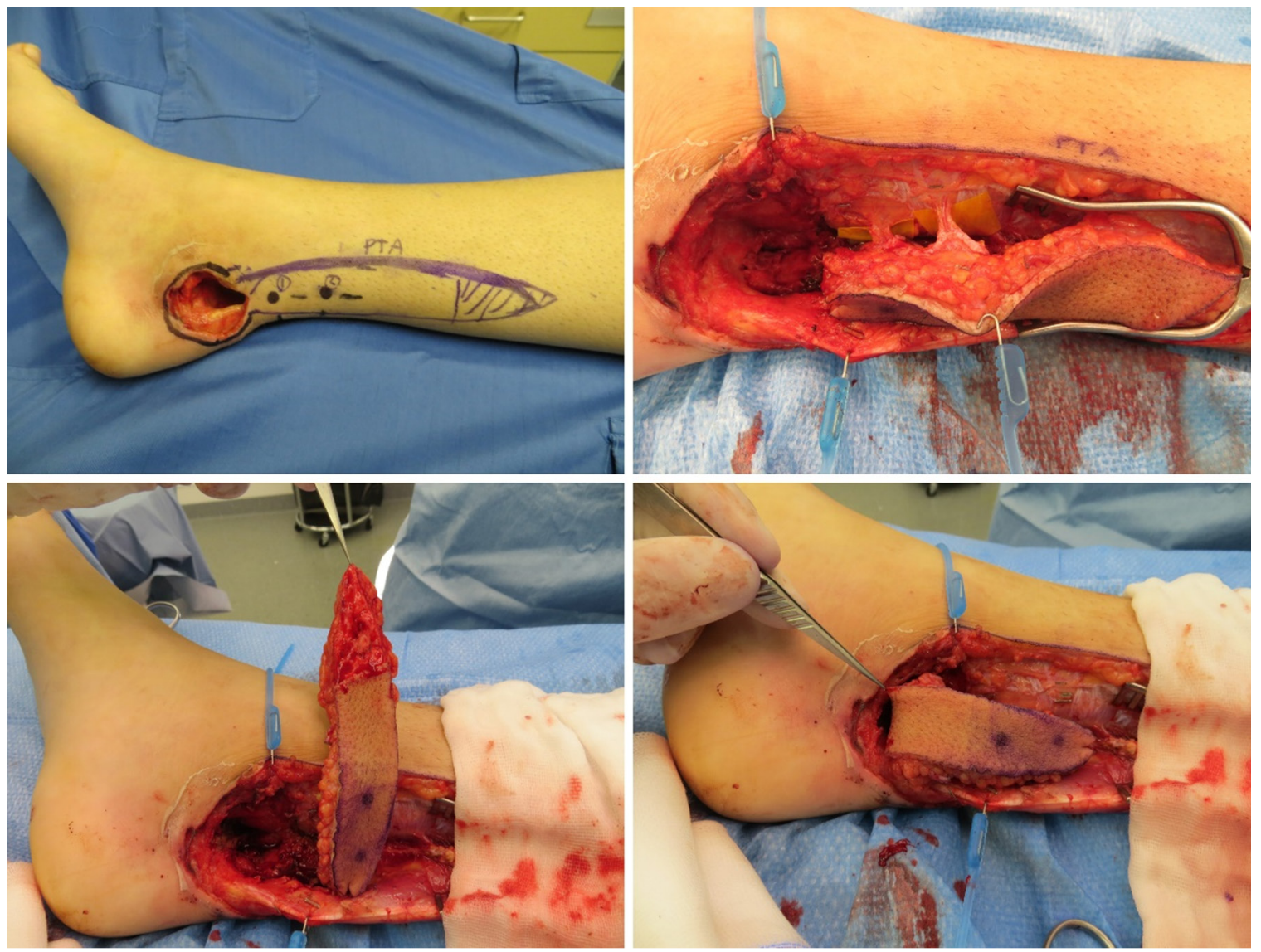

Figure 6. Upper left: penetrating injury of the distal lower limb dorsally to the medial ankle (after debridement), measuring $4 \mathrm{~cm} \times 3.5 \mathrm{~cm}$ $\times 2.5 \mathrm{~cm}$. Upper right: perforator flap measuring $12 \mathrm{~cm} \times 4 \mathrm{~cm}$ was harvested, based on a perforator of the posterior tibial artery. Another more distally located perforator was found but was ligated due to the close proximity of the wound. Lower left: the proximal tip of the flap was de-epithelized to fill the dead space. Lower right: the flap was rotated $180^{\circ}$ and filled the defect

\section{DISCUSSION}

The propeller flap is an extremely useful reconstructive tool and enables exceptional functional and cosmetic results in the lower extremity. Similar to a local flap, it provides the possibility of reconstructing "like with like", covering the defect with tissue of similar color and thickness but without the awkward dog ears. Being a perforator flap, it offers the freedom of choice regarding the skin island shape and dimension as well as a safe perfusion. Compared with a free flap, it requires a simpler operation without the need of microsurgical anastomosis and, thus, significantly shorter operating times. In a review of 21 studies, spanning from 2004 to 2012 and describing 310 propeller flaps, Nelson et al. ${ }^{[13]}$ noted a total flap loss in $5.5 \%$ and a partial flap loss in $11.6 \%$. Bekara et al. ${ }^{[14]}$ observed a $10.2 \%$ rate of partial necrosis and a $3.5 \%$ rate of complete necrosis in their meta-analysis of 40 publications on propeller flaps in lower limb reconstruction, representing 428 flaps and spanning from 2003 to 2014. These values are notably lower than those for free flaps in lower extremity, as observed by Wettstein et al. ${ }^{[15]}$. Furthermore, the decline of the complication rate seen when comparing the reviews of Nelson et al ${ }^{[13]}$ from 2013 and Bekara et al. ${ }^{[14]}$ from 2014 could imply a reduction of complications with the surgeons' experience.

Propeller flaps can be used to reconstruct many different types of defects of the lower extremity, both traumatic and non-traumatic in origin. Most commonly ${ }^{[14]}$, they are performed for coverage of primary defects in the distal third of the leg, as described by Teo ${ }^{[16]}$. More and more authors apply them in reconstructing the wounds of the foot, an example being the medial plantar artery perforator flap for 

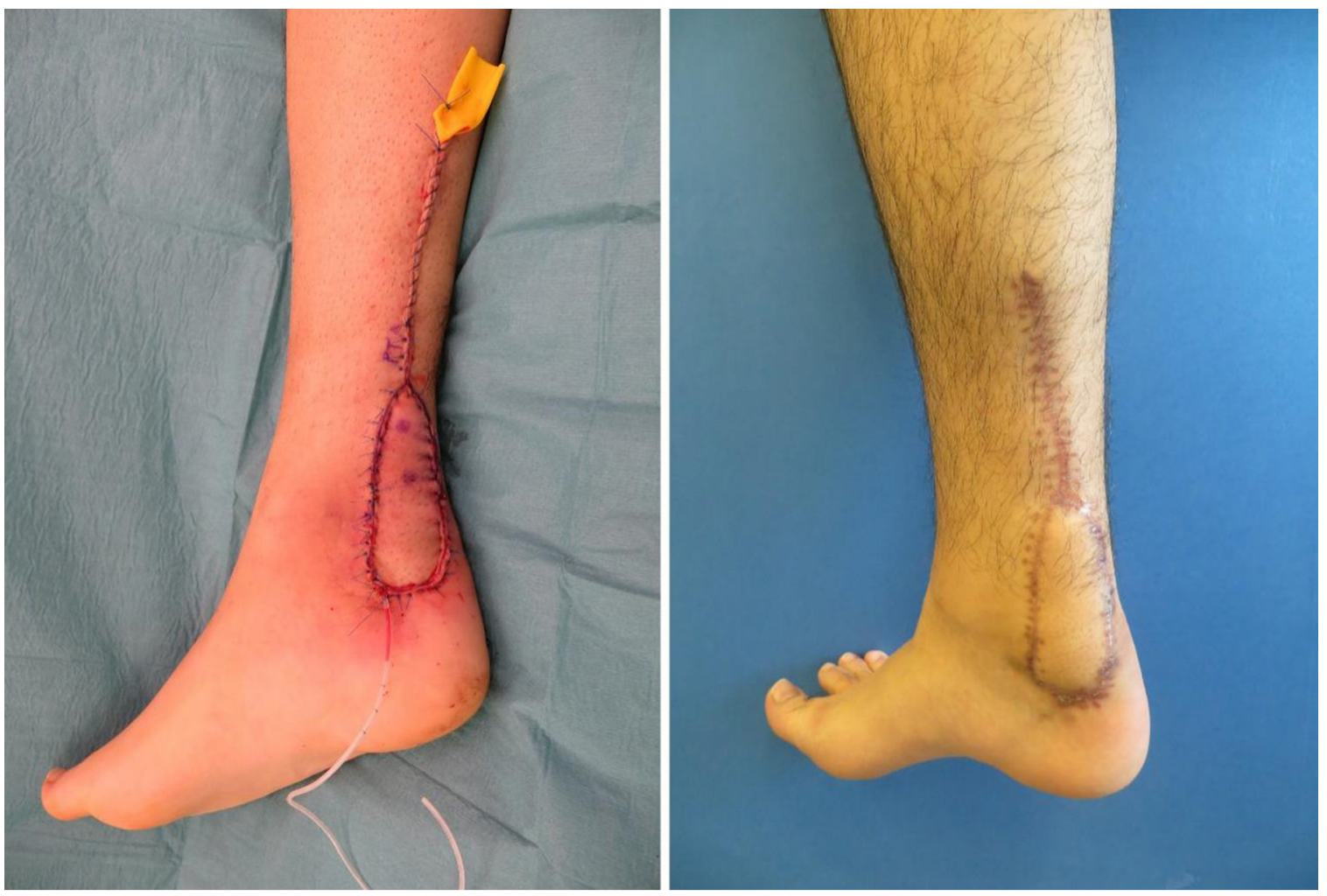

Figure 7. Left: the donor site was closed primarily without tension. Right: follow-up at 4 months, showing the functional and cosmetic result is satisfactory

reconstruction of the heel, middle foot sole, and plantar forefoot ${ }^{[17]}$. A large part of the scientific papers currently being published on this topic describes the closure of the secondary defects after free flap transfer from the lower extremity for use in other parts of the body, mostly head and neck reconstruction. Propeller flaps have been described for reconstruction of donor sites of anterolateral thigh flaps ${ }^{[12,18]}$, anteromedial thigh flaps ${ }^{[18]}$, vertical posteromedial thigh flaps ${ }^{[19]}$, and fibula flaps ${ }^{[20]}$. Furthermore, the propeller flap has even been used to cover the donor site of another propeller flap in the lower leg (sequential propeller flap) ${ }^{[1]]}$.

The dissection of propeller flaps in the literature is mostly subfascial ${ }^{[7,8,14,21]}$, which is easier to learn, safer, and faster than the suprafascial dissection. The suprafascial dissection is slower but leaves a less important donor-site defect and facilitates flap dissection at the sites where the intermuscular septa join the muscular fascia $^{[22]}$.

One of the biggest concerns when planning a propeller flap is the torsional twist of the pedicle. Teo ${ }^{[8]}$ showed that a single vascular pedicle is able to tolerate up to $180^{\circ}$ rotational twist without suffering vascular distress. The key to that is the radical skeletonization of the pedicle that divides all the fine fascial strands surrounding the vessels, allowing the flap to rotate $180^{\circ}$ without kinking of the vessels. Most authors systematically skeletonize the pedicle ${ }^{[8,9]}$ to allow for gentle spiral twist of the pedicle. It is logical to assume that the length of a vessel (l) is inversely proportional to the critical angle of twisting $(\Delta t)$, namely $\Delta t=[1 \times(1 / \Delta t)]$, and this has been proven by experimental studies ${ }^{[23,24]}$. Wong et al. ${ }^{[25]}$ performed nonlinear finite element simulations to elucidate the determinants of perforator patency in propeller flaps and proposed that the selected perforator should be approximately $1 \mathrm{~mm}$ in diameter and more than $30 \mathrm{~mm}$ in length. In our institution, the pedicle is always skeletonized for at least $3 \mathrm{~cm}$ and, if there are signs of venous congestion in ICG after insetting the flap, a further skeletonization of the pedicle is performed. 

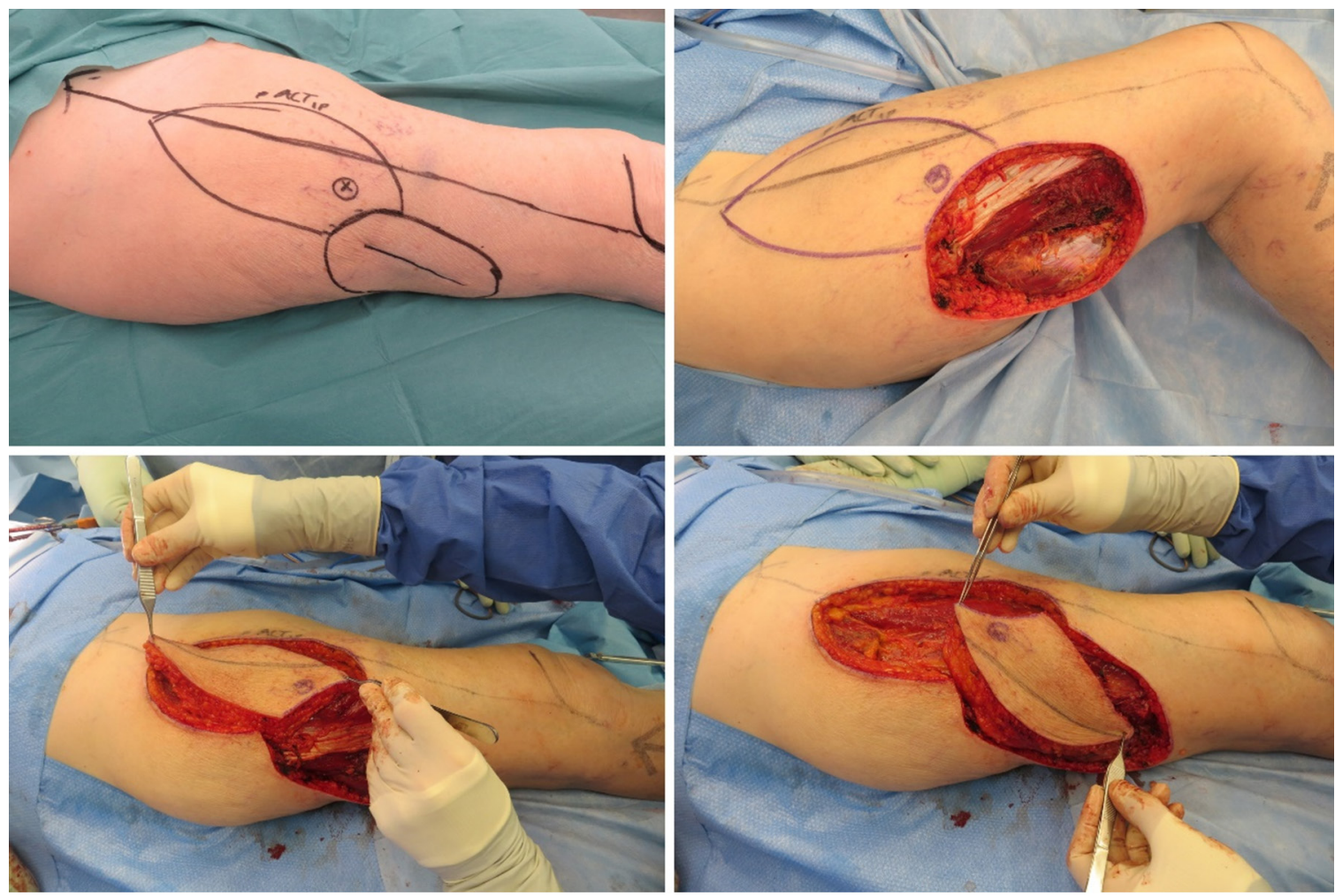

Figure 8. Upper left: preoperative markings of the sarcoma and the anterior lateral thigh flap design. The perforator was mapped using a handheld Doppler device. Upper right: large soft tissue defect on the lateral thigh with exposure of T ractus iliotibialis, M. vastus lateralis, and $\mathrm{M}$. biceps femoris. Lower left: The anterior lateral thigh flap, measuring $16 \mathrm{~cm} \times 8 \mathrm{~cm}$, was raised. Lower right: the flap was propelled into the defect $130^{\circ}$ counter clockwise, comfortably covering the defect
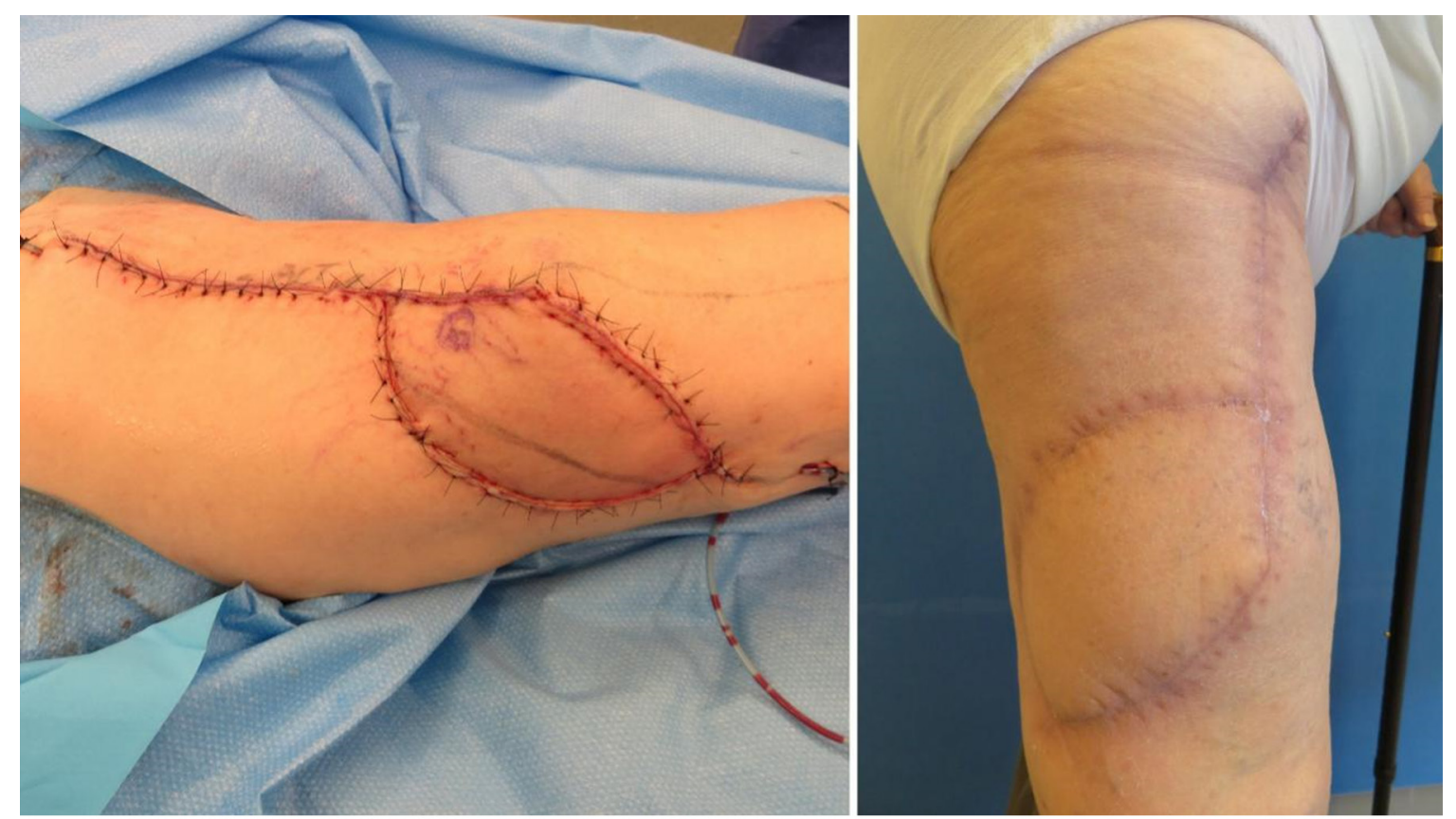

Figure 9. Left: primary closure of the donor site was possible without tension. Right: uneventful wound healing and no gait disturbance at five-month follow-up 
To date, there is no certain way of predicting preoperatively the exact size of the flap that will safely be perfused by one perforator. Nevertheless, there are possible technical refinements of the flap design and execution, which help improve the success rate by a large margin. Iida et al. ${ }^{[12]}$ proposed double-axes propeller flap, intraoperative ICG, and supercharging of the propeller flap to minimize the ratio of (partial) flap necrosis. When dissecting the flap, the perforators located farther than $3 \mathrm{~cm}$ from the main perforator are clamped and ligated. When perfusion seems insufficient in intraoperative ICG, supercharging can be performed using the ligated perforators.

Much research has been done into the correlation between the size of the perforator, its blood flow, and the volume of tissue it can sustain. Donski and Fodgestam ${ }^{[26]}$ proposed that the suprafascial interconnections between perforators lying along a septum effectively form an axial type flap, allowing for longer flaps to be designed. Taylor et al. ${ }^{[27]}$ demonstrated that a single vascular perforator can, in addition to its own angiosome, safely supply the angiosome of the adjacent perforator and, depending on the type of the anastomoses between the angiosomes (choke or true), even part of the territory of the perforator next to it. Saint-Cyr et al. ${ }^{[28]}$ described the perforasome theory based on the mechanism of opening "potential" vascular territories using linking vessels after ligation of adjacent perforators. Further studies should be conducted on defining the borders of perforasomes and the possibility of turning choke anastomoses into real anastomoses.

As for the significant risk factors for failure or complications for propeller flaps in lower limb reconstruction, Bekara et al. ${ }^{[14]}$ identified age older than 60 years, diabetes, and arteriopathy. Smoking did not significantly increase the complication rate. In a review of 119 studies from 1991 to 2015, comprising 1315 propeller flaps in different areas of the body, Sisti et al. ${ }^{[29]}$ found that the complication rate for propeller flaps was by far the highest in the lower limb (31.8\%), compared to trunk (19.5\%), head and neck (15.7\%), and upper limb (15.9\%).

\section{CONCLUSION}

The perforator-pedicled flap has been gaining popularity among plastic surgeons over the past 20 years. In our experience, it is an excellent option for lower limb soft tissue reconstruction in appropriately chosen patients, enabling a functional and aesthetically pleasing result.

\section{DECLARATIONS}

\section{Authors' contributions}

Senior author and corresponding, performed all surgeries and revised the manuscript: Scaglioni MF

Wrote the manuscript under Scagloni supervision: Macek A

\section{Availability of data and materials}

Data from Scaglioni MF, Department of Plastic Surgery Lucerne.

\section{Financial support and sponsorship}

Not applicable.

\section{Conflicts of interest}

All authors declared that there are no conflicts of interest.

\section{Ethical approval and consent to participate}

Followed Helsinki Guidelines, Case reports with review. 


\section{Consent for publication}

Not applicable.

\section{Copyright}

(c) The Author(s) 2019.

\section{REFERENCES}

1. Reddy V, Stevenson TR. MOC-PS (SM) CME article: lower extremity reconstruction. Plast Reconstr Surg 2008;121:1-7.

2. Hallock GG. Lower extremity muscle perforator flaps for lower extremity reconstruction. Plast Reconstr Surg 2004;114:1123-30.

3. Ponten B. The fasciocutaneous flap: its use in soft tissue defects of the lower leg. Br J Plast Surg 1981;34:215-20.

4. Khouri RK, Shaw WW. Reconstruction of the lower extremity with microvascular free flaps: a 10-year experience with 304 consecutive cases. J Trauma 1989;29:1086-94.

5. Hyakusoku H, Yamamoto T, Fumiiri M. The propeller flap method. Br J Plast Surg 1991;44:53-4.

6. Koshima I, Soeda S. Inferior epigastric artery skin flaps without rectus abdominis muscle. Br J Plast Surg 1989;42:645-8.

7. Hallock GG. The propeller flap version of the adductor muscle perforator flap for coverage of ischial or trochanteric pressure sores. Ann Plast Surg 2006;56:540-2.

8. Teo TC. The propeller flap concept. Clin Plast Surg 2010;37:615-26.

9. Pignatti M, Ogawa R, Hallock GG, Mateev M, Georgescu AV, et al. The "Tokyo" consensus on propeller flaps. Plast Reconstr Surg 2011;127:716-22.

10. Blondeel PN, Van Landuyt K, Monstrey SJ, Hamdi M, Matton GE, et al. The “Gent" consensus on perforator flap terminology: preliminary definitions. Plast Reconstr Surg 2003;112:1378-83.

11. Scaglioni MF, Franchi A, Fritsche E. Propeller flap donor site closure by means of another propeller flap: a case report and literature review. Microsurgery 2019; Epub ahead of print doi: 10.1002/micr.30497

12. Iida T, Yoshimatsu H, Koshima I. Reconstruction of anterolateral thigh defects using perforator-based propeller flaps. Ann Plast Surg 2017;79:385-9.

13. Nelson JA, Fischer JP, Brazio PS, Kovach SJ, Rosson GD, et al. A review of propeller flaps for distal lower extremity soft tissue reconstruction: is flap loss too high? Microsurgery 2013;33:578-86.

14. Bekara F, Herlin C, Mojallal A, Sinna R, Ayestaray B, et al. A systematic review and meta-analysis of perforator-pedicled propeller flaps in lower extremity defects: identification of risk factors for complications. Plast Reconstr Surg 2016;137:314-31.

15. Wettstein R, Schürch R, Banic A, Erni D, Harder Y. Review of 197 consecutive free flap reconstructions in the lower extremity. J Plast Reconstr Aesthet Surg 2008;61:772-6.

16. Teo TC. Perforator local flaps in lower limb reconstruction. Cir Plast Ibero-Latinoamericana 2006;32:15-6.

17. Scaglioni MF, Rittirsch D, Giovanoli P. Reconstruction of the heel, middle foot sole, and plantar forefoot with the medial plantar artery perforator flap: clinical experience with 28 cases. Plast Reconstr Surg 2018;141:200-8.

18. Hung KS, Chen SH, Chen WC, Tseng WL, Lee YC. Surgical algorithmic approach to facilitate primary closure of the anterolateral thigh flap donor site in head and neck reconstruction. Ann Plast Surg 2018; Epub ahead of print doi: 10.1097/SAP.0000000000001729

19. Scaglioni MF, Barth AA, Chen YC. Perforator flap based on the third perforator of the profunda femoris artery (PFA)-assisted closure of the free vertical posteromedial thigh (vPMT) flap donor site. Microsurgery 2018;38:758-62.

20. Sharma M, Balasubramanian D, Thankappan K, Sampathirao CL, Mathew J, et al. Propeller flaps in the closure of free fibula flap donor site skin defects. Ann Plast Surg 2013;71:76-9.

21. Moscatiello F, Masià J, Carrera A, Clavero JA, Larrañaga JR, et al. The 'propeller' distal anteromedial thigh perforator flap: anatomic study and clinical applications. J Plast Reconstr Aesthet Surg 2007;60:1323-30.

22. Chaput B, Herlin C, Bekara F, Bertheuil N. Thinning: the difference between free and propeller perforator flaps. Arch Plast Surg 2015;42:241-2.

23. Bravo FG, Schwarze HP. Free-style local perforator flaps: concept and classification system. J Plast Reconstr Aesthet Surg 2009;62:602-8.

24. Bilgin SS, Topalan M, Ip WY, Chow SP. Effect of torsion on microvenous anastomotic patency in a rat model and early thrombolytic phenomenon. Microsurgery 2003;23:381-6.

25. Wong CH, Cui F, Tan BK, Liu Z, Lee HP, et al. Nonlinear finite element simulations to elucidate the determinants of perforator patency in propeller flaps. Ann Plast Surg 2007;59:672-8.

26. Donski PK, Fogdestam I. Distally based fasciocutaneous flap from the sural region. A preliminary report. Scand J Plast Reconstr Surg 1983;17:191-6.

27. Taylor GI, Corlett RJ, Ashton MW. The functional angiosome: clinical implications of the anatomical concept. Plast Reconstr Surg 2017;140:721-33.

28. Saint-Cyr M, Schaverien M, Arbique G, Hatef D, Brown SA, et al. Three- and four-dimensional computed tomographic angiography and venography for the investigation of the vascular anatomy and perfusion of perforator flaps. Plast Reconstr Surg 2008;121:772-80.

29. Sisti A, D’Aniello C, Fortezza L, Tassinari J, Cuomo R, et al. Propeller flaps: a literature review. In Vivo 2016;30:351-73. 